\title{
Una aproximación a la historia medieval en Galicia entre los años 2007 y 2017
}

\section{The Medieval History in Galicia between 2007 and 2017: An Approximation}

\author{
Carmen Álvarez García \\ Universidad Nacional de \\ Educación a Distancia (España) \\ alvgarcarmen@yahoo.es
}

\section{Resumen}

Este artículo tiene como propósito principal el identificar las líneas de investigación de los trabajos producidos en Galicia (España) entre los años 2007 y 2017. Para ello, se analizan artículos y libros de medievalistas gallegos y se clasifican dentro del llamado campo historiográfico gallego. Se incluyen tanto las tendencias emergentes y minoritarias como las consolidadas. Como explicamos allí, esta producción forma parte de la propia evolución de la historiografía española y europea del período.

\section{Palabras clave}

Historiografía gallega, historia medieval, historia política, organización social del territorio.

\begin{abstract}
This article attempts to identify the lines of research of the works produced in Galicia (Spain) between 2007 and 2017. We shall examine articles and books written by Galician medievalists and classify them within the so called Galician historiographic field. The different trends both the emergent, minority and consolidated ones have also been included. As we explain there, this production takes part of the evolution of the Spanish and European historiography in that period.
\end{abstract}

\section{Keywords}

Galician historiography, medieval history, political history, social organization of the territory. 


\section{Introducción}

La investigación medieval constituye un campo académico y científico en el que se produce un dialogo e interacción entre aquellos investigadores que entran dentro del discurso dominante y aquellos otros que buscan otras vías de investigación. Tanto unos como otros están insertos, en nuestro caso, en la sociedad gallega de la que forman parte y a la que debe revertir el resultado de sus estudios. En el presente artículo utilizaremos el concepto de "historiografía inmediata" para reconocer tendencias y sintetizar líneas de investigación que han tenido lugar en Galicia entre 2007 y 2017.

Tomando como principios básicos el concepto de "campo" de Bourdieu' y la "historiografía inmediata" nos hemos acercado a las instituciones, revistas e investigadores imbricados en la investigación sobre el medievalismo en Galicia. En cuanto a las instituciones son principalmente las universidades de Santiago de Compostela y de Vigo, además del CSIC a través del Instituto de Estudios Gallegos Padre Sarmiento (IEGPS). Todas ellas poseen departamentos de Historia Medieval con equipos de medievalistas dedicados a la investigación en los diferentes campos científicos. Para la recopilación de artículos hemos rastreado las revistas científicas que con carácter periódico se editan en Galicia, como Semata, Compostellanum o Cuaderno de Estudios Gallegos. Para las monografías hemos recurrido a los servicios de publicaciones que las instituciones académicas, como editores, publican. Por último, en cuanto a los medievalistas, hemos rastreado los investigadores que han estado activos en los diez años contemplados y hemos tratado de desentrañar los temas que han centrado los trabajos publicados en Galicia.

Para realizar esta tarea comenzaremos por anclar los conceptos sobre los que se desarrollará nuestro estudio. Continuaremos analizando las diferentes tendencias historiográficas de la historia medieval en Galicia en el periodo estudiado. Y finalizaremos con unas conclusiones.

\section{El campo historiográfico de la historia medieval en Galicia}

Antes de comenzar debemos mencionar dos artículos imprescindibles para conocer el campo de la historiografía medieval gallega en los últimos treinta años. Mari Carmen Pallares y Ermelindo Portela repasan la producción científica del medievalismo gallego entre los años 1976 y 1986. ${ }^{2}$ Unos años después, Pérez Rodríguez toma el testigo y estudia la historiografía en nuestro campo entre los años 1988-2008. ${ }^{3}$ Estos dos trabajos nos muestran los temas que la investigación ha abordado y su evolución en el tiempo así como los diferentes tratamientos historiográficos que se da en cada uno de los trabajos.

En Galicia el foco de la renovación metodológica en el medievalismo parte de la Universidad de Santiago de Compostela bajo la dirección de José Ángel García de Cortázar, a donde llega en los inicios de los años setenta y donde permanece hasta 1978. Cortázar ya había publicado su trabajo sobre el monasterio sobre San Millán de la

\footnotetext{
${ }^{1}$ Pierre Bourdieu, El oficio de científico (Barcelona: Anagrama, 2003), 17-40.

2 María del Carmen Pallares Méndez y Ermelindo Portela Silva, "Historiografía sobre la edad media de Galicia en los diez últimos años (1976-1986)", Studia historica. Historia medieval, 6 (1988): 7-26.

${ }^{3}$ Francisco Pérez Rodríguez, "Historia Medieval de Galicia: un balance historiográfico (1988-2008)", Minius, 18 (2010): 59-146.
} 
Cogolla ${ }^{4}$ en el que introduce el análisis regional y las estructuras sociales, revisando las fuentes en busca de elementos demográficos, económicos y sociales, de clara influencia de la escuela de los Annales. Este trabajo será un referente que abrirá una nueva forma de hacer historia. En 1973 en las I Jornadas de Metodología Aplicada a las Ciencias históricas desarrolladas en la Universidad de Santiago de Compostela presenta la ponencia "La economía rural medieval: un esquema de análisis histórico de base regional". Este trabajo tiene su continuación en "La economía rural medieval: un esquema de análisis estructural de sus contenidos a través del ejemplo hispanocristiano", obra de referencia en el que el método expuesto aúna el estudio espacial, las formas de propiedad agraria, la explotación de la tierra y la renta agraria.

Creemos importante detenernos en la llegada de Cortázar a la Universidad de Santiago de Compostela ya que su influencia en la historiografía gallega llega hasta nuestros días, a través del equipo que formó. La primera tesis que dirigió fue la de Ermelindo Portela, ${ }^{5}$ cuyas líneas de investigación han estado vertebradas por los estudios territoriales y por los de la organización social del espacio, como lo definió Cortázar, quien además dirigió las tesis doctorales de Mari Carmen Pallares, ${ }^{6}$ Mercedes Durany, ${ }^{7}$ Fernando López Alsina ${ }^{8}$ y M. Luz Ríos ${ }^{9}$ (1990). Todos ellos han desarrollado su trabajo en universidades gallegas, Pallares, Alsina y Ríos en la Universidad de Santiago de Compostela mientras que Durany lo ha hecho en la Universidad de Vigo.

Ermelindo Portela a su vez fue director de tesis, entre otros, de Ferreira Priegue ${ }^{10}$ en 1886, en 1990 de Carlos Baliñas Pérez ${ }^{11}$, en 1993 de Andrade Cernadas ${ }^{12}$, López Carreira $^{13}$ en 1994, F. Javier Pérez Rodríguez también en el año 1994, Xose Manuel Sánchez Sánchez en 2006 y en 2014 la tesis doctoral de Ana Paula Leite Rodrigues. ${ }^{14}$ Esto nos muestra que el relevo generacional está asegurado y que se siguen formando

\footnotetext{
${ }^{4}$ José A. García de Cortázar y Ruíz de Aguirre, El dominio del Monasterio de San Millán de la Cogolla (siglos X-XIII). Introducción a la historia rural de Castilla altomedieval (Salamanca: Universidad de Salamanca, 1969).

${ }^{5}$ Ermelindo Portela Silva, La región del Obispado de Tuy en los siglos XII al XV. Una sociedad en la expansión y en la crisis, (Santiago de Compostela: Universidad de Santiago de Compostela, 1972).

${ }^{6}$ María del Carmen Pallares Mendez, Estructura y evolución del dominio del Monasterio de Sobrado en la Edad Media (900-1300) (Santiago de Compostela: Universidad de Santiago de Compostela, 1977).

${ }^{7}$ Mercedes Durany Castillo, La región del Bierzo desde finales del siglo IX hasta mediados el siglo XIII el proceso de ocupación y organización social del espacio (Santiago de Compostela: Universidad de Santiago de Compostela, 1987).

${ }^{8}$ Fernando López Alsina, La ciudad de Santiago de Compostela en la Alta Edad Media (años 800-1150) (Santiago de Compostela: Universidad Santiago de Compostela, 1986)

${ }^{9}$ María Luz Ríos Rodríguez, Relaciones contractuales agrarias en la Galicia medieval: los orígenes del foro (1150-1350) (Santiago de Compostela: Universidad Santiago de Compostela, 1990).

${ }^{10}$ Elisa Ferreira Prieguez, E. M.: Galicia en el comercio marítimo medieval (Santiago de Compostela: Universidad Santiago de Compostela, 1986).

${ }^{11}$ Carlos Baliñas Pérez, Do mito á realidade: a definición social e territorial de Galicia na Alta Idade Media (séculos VIII e IX) (Santiago de Compostela: Universidad Santiago de Compostela, 1990).

${ }^{12}$ José Miguel Andrade Cernadas, Las transformaciones de la sociedad gallega en los siglos XI al XIII: el papel de los monjes negros, tesis doctoral (Santiago de Compostela: Universidad Santiago de Compostela, 1993.

13 Anselmo López Carreira, A Cidade de Ourense no século XV: sociedade urbana na Galicia baixomedieval (Santiago de Compostela: Universidad Santiago de Compostela, 1994).

14 Ana P. Leite Rodrigues, Senhores e camponeses num espaço de fronteira: estudo da projecçao portuguesa do domínio monástico de Santa Maria de Oia nos séculos XII a XV, (Santiago de Compostela: Universidad Santiago de Compostela, 2014).
} 
medievalistas tanto en la Universidad de Santiago de Compostela como en la Universidad de Vigo.

En cuanto al marco teórico, durante los años 80 hay una cierta influencia de las grandes escuelas historiográficas, la escuela de los Annales y la escuela marxista. Un ejemplo puede ser la tesis doctoral de Carlos Barros Mentalidad y revuelta en la Galicia irmandiña: favorables y contrarios. ${ }^{15}$ Con esta obra Carlos Barros aúna la escuela marxista con la historia de las mentalidades, que será una de sus principales líneas de investigación.

Los años noventa se caracterizan, como en el resto de España, por la diversidad metodológica donde conviven temas nuevos y otros tradicionales con planteamientos renovados. Dos ejemplos de viejos temas que se estudian con metodologías renovadas son: Orixes do foro na Galicia Medieval ${ }^{16}$ y La sociedad gallega en la Alta Edad Media. ${ }^{17}$ Esta última pone en cuestión el despoblamiento de Galicia tras la invasión musulmana. Ríos renueva el tratamiento del tema del foro en la historia medieval gallega. Por otro lado, se incorporan temas nuevos como la Historia de las Mujeres, de la que Mari Carmen Pallares ${ }^{18}$ es pionera en Galicia. A esta investigadora, junto a Ermelindo Portela, también debemos el inicio del tratamiento de la renovación de la biografía en 1998. Ya en el los inicios del presente siglo M. Carmen Pallares y Ermelindo Portela publican La reina Urraca y el obispo Gelmírez: Nabot contra Jezabel, en la línea de la biografía política. La historia política es otro campo que renovará su metodología en estos años, en este sentido son pioneros los trabajos de Ermelindo Portela "Galicia en la época de Alfonso III" y "Galicia y los reyes de Oviedo". ${ }^{20}$

En los años noventa la historia de las mentalidades muestra cierto desarrollo. Ahí están los trabajos de medievalistas Carlos Barros, José M. Andrade o Mari Luz Ríos, además de los estudios sobre la muerte realizados por Ermelindo Portela o Mari Carmen Pallares. Dentro de ese ámbito de las Mentalidades, en 1991 tiene lugar el congreso Xudeus e conversos na Historia ${ }^{21}$ celebrado en Rivadavia (Orense), que dio lugar a dos volúmenes publicados donde se reflejaron las comunicaciones del congreso. En otro sentido, 1993 tiene lugar el primer congreso internacional "Historia a Debate", el cual tuvo tres ediciones más en los años 1999, 2004 y 2010. Los Congresos de Historia a Debate se convierten en referencias importantes para la comunidad de historiadores, nacionales e internacionales, gracias a la ingente labor de su coordinador, el profesor

${ }^{15}$ Barros Guimares, C.: Mentalidad y revuelta en la Galicia irmandiña: favorables y contrarios, tesis doctoral, Universidad Santiago de Compostela, 1989.

16 María Luz Ríos Rodríguez, Orixes do foro na Galicia Medieval (Santiago de Compostela: Universidade de Santiago de Compostela, 1993).

17 Amancio Isla Frez, La sociedad gallega en la alta edad media (Madrid: Consejo Superior de Investigaciones Científicas, 1992).

${ }^{18}$ María del Carmen Pallares Mendez, Vida das mulleres na Galicia medieval: 1100-1500 (Santiago de Compostela: Universidad de Santiago de Compostela, 1993.

${ }_{19}$ Ermelindo Portela Silva, "Galicia en la época de Alfonso III" en La época de Alfonso III y San Salvador de Valdediós: Congreso de Historia Medieval Oviedo, 1993, Francisco Javier Fernández Conde (coord.) (Oviedo: Universidad de Oviedo, 1994), 79-96.

${ }^{20}$ Ermelindo Portela Silva, "Galicia y los reyes de Oviedo", en La época de la Monarquía Asturiana: actas del simposio celebrado en Covadonga (Oviedo: Real Instituto de Estudios Asturianos, 2002), 351366.

${ }^{21}$ Carlos Barros Guimerans, Xudeus e conversos na historia. Actas do Congreso Internacional, Ribadavia 14-17 de outubro de 1991 (Santiago de Compostela, 1994). 
Carlos Barros. Los Congresos dejaron un total de quince volúmenes de Actas, con un tomo dedicado al Medievo, ${ }^{22}$ de gran repercusión. Además, Historia a Debate se convirtió en una comunidad-red internacional de historiadores que se reunían diariamente a través de su web www.h-debate.com y de sus listas de distribución. Con los años, y ya en el año 2001, se transformó además, a partir de la realización del Manifiesto historiográfico Historia a Debate, en un intento de crear una alternativa historiográfica latina. Con la idea de afrontar la empresa de pensar la historia desde un lugar periférico como España y no depender de los centros historiográficos tradicionales. La iniciativa presentaba un interés poco habitual por la historiografía, la metodología y la teoría de la historia. ${ }^{23}$

Ya en el presente siglo, al estudio de los grandes personajes, se suma el de la nobleza gallega y heráldica de los siglos XIV y XV, tema en el que destaca Eduardo Pardo de Guevara, que llega a Galicia en el año 1994 para hacerse cargo del Instituto de Estudios Gallegos, Padre Sarmiento (IEGPS) adscrito al CSIC. En la actualidad el ámbito de estudio de esta institución se centra en la Historia con prioridad en los estudios de parentesco y redes de poder en la Edad Media. ${ }^{24}$ Otras líneas de investigación de esta institución, además de las expuestas, son la diplomática, la epigráfica y las peregrinaciones.

A partir del año 2000 los estudios se continúan multiplicando al aumentar los historiadores dedicados a la Edad Media. Y también las instituciones ya que en los años noventa se había creado la facultad de geografía e historia en el campus de Orense de la Universidad de Vigo. No obstante el eje sobre el que pivota la investigación medievalista continúa siendo la Universidad de Santiago de Compostela. También debemos mencionar, como ya hemos apuntado, al Instituto de Estudios Gallegos Padre Sarmiento del CSIC cuya titularidad es compartida desde el año 2000 con la Xunta de Galicia. Sin olvidarnos del Instituto de Estudios Jacobeos, creado en 1954 que nos parece interesante para la Historia de la Iglesia.

Aun no contando en Galicia con ninguna revista científica especializada de historia medieval, sí se publican con profusión artículos de este período en revistas generalistas. De todas ellas destacamos cuatro por estar vinculas cada una de ellas a sendas instituciones: 1) Sémata: Ciencias Sociales e Humanidades. Publicada por la Universidad de Santiago de Compostela, es de carácter anual, nace en 1988 y se tratan temas de modo monográfico de la áreas de Geografía, Historia e Historia del Arte; 2) Compostellanum. De la archidiócesis de Santiago de Compostela. Nace en 1956 y publica cuatro números al año, dos de investigación teológica y los otros dos de Historia centrados, principalmente, de la historia de Santiago; 3) Cuadernos de Estudios Gallegos, publicación del Instituto de Estudios Gallegos Padre Sarmiento del CSIC. Se publica desde 1941 y es de carácter anual; 4) Estudios Mindoñenses. Anuario de estudios histórico-teológicos de la diócesis de Mondoñedo-Ferrol.

\footnotetext{
${ }^{22}$ Carlos Barros Guimerans, Historia a Debate: Medieval (Satiago de COmpostel aXunta de Galicia, Santiago de Compostela, 1995)

${ }^{23}$ Israel Sanmartín Barros, "Historia a Debate como una comunidad científica de historiadores críticos en red (1993-2004)", en Historia a debate: actas del III Congreso Internacional "Historia a Debate", Carlos Barros (ed.), (Santiago de Compostela: Historia a Debate, 2004), 265-284.

${ }^{24}$ Ver "IEGPS-Instituto de Estudios Gallegos Padre Sarmiento", http://www.iegps.csic.es/, [19-05-2019]
} 


\section{La historiografía inmediata en el campo del medievalismo gallego, 2007-2017}

A continuación vamos a estudiar las líneas de investigación que sigue el medievalismo gallego y, por tanto las luchas científicas entre las diferentes formas de escribir la historia y cuales tienen mayor dimensión. Hemos manejado un total de doscientas noventa y dos referencias, para hacer la selección de los trabajos nos hemos basado en lo publicado por los medievalistas gallegos, con la mirada puesta en los servicios de publicaciones de las diferentes instituciones gallegas de las que emana el trabajo científico. También hemos tenido en cuenta la obra que se realizan desde Galicia y se publica en el ámbito español e internacional.

\section{Las tendencias historiográficas predominantes}

En primer lugar abordaremos las tendencias historiográficas predominantes en la historia medieval realizada en Galicia. La organización social del territorio y la historia política son las más importantes.

\section{La historia de la organización social del territorio / historia rural}

Historia rural, económico social o, como la denomina Cortázar, organización social del espacio, tiene gran tradición en Galicia, como ya hemos comentado. Algunos de los trabajos que hemos mencionado en otros apartados podrían estar también aquí pero pensamos que tienen características que los diferencian. De la producción científica publicada en estos diez años destacaremos solo cinco que creemos, son representativos por los temas tratados y los investigadores que los realizan.

Comenzamos con María del Carmen Pallares y Ermelindo Portela que publican el artículo "El lugar de los campesinos. De repobladores a repoblados",25 dentro de la monografía El lugar del campesino: en torno a la obra de Reyna Pastor. Mari Carmen Pallares y Ermelindo Portela analizan la estructura social del campesinado y, con esta investigación, contribuyen a renovar el medievalismo español. Si Mari Carmen Pallares y Ermelindo Portela tratan el tema de los campesinos, Mari Luz Ríos en "Apropiación y organización social de un medio natural: pesca fluvial y pesqueras en la Galicia medieval" ${ }^{26}$ nos adentra en la importancia de la pesca en el mundo rural.

El trabajo de Mercedes Durany, del campus de Ourense de la Universidad de Vigo, El espacio berciano en la Edad Media, punto de partida y escenario de nuestras investigaciones, ${ }^{27}$ no es un trabajo sobre Galicia pero su autora forma parte de la comunidad del medievalismo gallego. Por otra parte, Andrade Cernadas estudia el

\footnotetext{
25 María del Carmen Pallares Mendez y Ermelindo Portela Silva, "El lugar de los campesinos. De repobladores a repoblados", en El lugar del campesino: en torno a la obra de Reyna Pastor, Ana Rodríguez (ed.) (Valencia, CSIC y Universidad de Valencia, 2007), 61-88.

${ }^{26}$ María Luz Ríos Rodríguez, "Apropiación y organización social de un medio natural: pesca fluvial y pesqueras en la Galicia medieval”, en Mundos medievales: espacios, sociedades y poder: homenaje al profesor José Ángel García de Cortázar y Ruiz de Aguirre, Vol. 2, (Santander: Universidad de Cantabria, 2012), 1827-1842.

${ }^{27}$ Mercedes Durany Castrillo, "El espacio berciano en la Edad Media, punto de partida y escenario de nuestras investigaciones", en Mundos medievales: espacios, sociedades y poder: homenaje al profesor José Ángel García de Cortázar y Ruiz de Aguirre, Vol. 1, (Santander: Universidad de Cantabria, 2012), 105-118.
} 
protagonismo de los monasterios en la articulación de la sociedad rural en: "El protagonismo de monasterios y conventos en la agricultura y el mundo rural gallego a lo largo de la historia. Monasterios y conventos gallegos en la Edad Media: su influencia en la agricultura y en el mundo rural". ${ }^{28}$

Fernando López Alsina, de la Universidad de Santiago de Compostela, que tiene en la historia urbana una de sus líneas de investigación, le traemos aquí por sus investigaciones sobre la ordenación del territorio. En La articulación de las unidades de organización social del espacio en Galicia durante la Edad Media: Villa, Parroquia, Terra analiza las diferentes unidades en las que se estructura el territorio en Galicia, desde las más pequeñas (villas) a las unidades más grandes que engloban un número considerable de parroquias, Terra, el "característico distrito para el ejercicio del poder". ${ }^{29}$ Esta estructura del territorio se consolida y es donde se ejerce el poder, se desarrolla la vida social y se refuerzan los vínculos entre sus los habitantes. En "Da protoparroquia ou parroquia antiga altomedieval á parroquia clásica en Galicia". Alsina ${ }^{30}$ estudia la evolución de esta unidad del entramado territorial.

\section{La historia política}

La historia política es uno de los campos más desarrollados en el medievalismo gallego. En esta línea temática encontramos dos caminos que dominan el panorama, la biografía y la frontera, y añadimos un tercero donde incluimos otros temas:

1) La biografía política, ${ }^{31}$ Ermelindo Portela utiliza la biografía como medio metodológico en sus estudios sobre Gelmírez, Arzobispo de Santiago entre 1100 y 1140 cuya vida y acciones son glosadas en la Historia Compostelana, (crónica escrita por encargo del propio Gelmírez). Entre ellos destacamos la monografía Diego Gelmírez (c.1065-1140). El báculo y la ballesta, trabajo en el que Portela nos muestra el perfil político de Gelmirez, su relación con el papado y con personajes como Alfonso VI, Raimundo de Borgoña o la reina Urraca I y Alfonso VII, entre otros. Gelmirez es también el protagonista de "Diego Gelmírez y el trono de Hispania: la coronación real del año 1111". Ermelindo Portela refiere las circunstancias que le llevan a coronar como rey de Galicia a Alfonso VII. ${ }^{32}$ En Alfonso VI y Galicia: territorio y poder, Portela

\footnotetext{
28 José Miguel Andrade Cernadas, "El protagonismo de monasterios y conventos en la agricultura y el mundo rural gallego a lo largo de la historia. Monasterios y conventos gallegos en la Edad Media: su influencia en la agricultura y en el mundo rural", en El protagonismo monástico a través de la historia fotografía, Vol. 1, José Miguel Andrade Cernadas J. M. et al. (ed.), (A Coruña: Ediciones Hércules, 2016), 113-149.

${ }^{29}$ Fernando López Alsina, "La articulación de las unidades de organización social del espacio en Galicia durante la Edad Media: Villa, Parroquia, Terra", en La pervivencia del concepto: nuevas reflexiones sobre la ordenación social del espacio en la Edad Media, José Ángel Sesma Muñoz y Carlos Laliena Corbera (Zaragoza: Universidad de Zaragoza, 2008), 76-84.

${ }^{30}$ Fernando López Alsina, "Da protoparroquia ou parroquia antiga altomedieval á parroquia clásica en Galicia”, en A Parroquia en Galicia: pasado, presente e futuro, Fernando García Pazos (ed.), (Santiago de Compostela: Xunta de Galicia, 2009), 57-75.

${ }^{31}$ La publicación del libro de Ermelindo Portela Silva, García II de Galicia. El Rey y el Reino (10651090), (Burgos: La Olmeda, 2001) supuso la renovación del estudio de los grandes personajes a través de la biografía. En este trabajo, Ermelindo Portela se acerca al rey García II a través de los conflictos políticos a los que tiene que hacer frente en su reinado. Cambiando la visión que la historiografía había vertido sobre él.

${ }^{32}$ Ermelindo Portela Silva, "Diego Gelmírez y el trono de Hispania: la coronación real del año 1111" (Santiago de Compostela: Consello da Cultura Galega, 2013), 45-75.
} 
vuelve a usar la biografía como método para, a través del personaje, hacer historia política. José miguel Andrade también utiliza la biografía para acercarnos al personaje inserto en su época. Lo vemos en el artículo "El abad Pedro I de Celanova (1091-1119): una primera aproximación"33 y en la monografía Alfonso II "el Casto", ${ }^{34}$ dedicada al rey astur muy vinculado a Galicia y en cuyo reinado se identificó el sepulcro de Santiago Apóstol.

2) El segundo es la cuestión de la frontera donde Santa María de Oia en su contexto fronterizo es ampliamente tratada por diversos investigadores. Destacamos el trabajo que Ermelindo Portela dedica al origen del Monasterio ${ }^{35}$ en el que hace un análisis de las reformas eclesiásticas, pero sin perder de vista el factor político que adquiere al encontrarse en un espacio de frontera. A través de la documentación de este monasterio y de las Vitae de S. Teotónio e S. Rosendo, Leite Rodrigues estudia la utilización política de lo sagrado en el nacimiento de Portugal y la frontera con Galicia. $^{36}$ Las relaciones entre Portugal y Galicia es tratado por diferentes investigadores, desde el Instituto de Estudios Gallegos Padre Sarmiento. Desde el CSIC, Otero Piñeyro Maseda y Pardo de Guevara tratan el tema en A Galiza nas suas relações com Portugal. Paz Romero, de la Universidad de A Coruña, a través del estudio sistemático de la documentación y teniendo en cuenta diferentes aspectos como los económicos, familiares o geográficos, trata el tema de frontera entre los reinos de León-Castilla y Portugal. ${ }^{37}$

3) Ermelindo Portela y Mari Carmen Pallares, en "De la función de los castillos en el tiempo y los espacios de Diego Gelmírez", 38 nos dan las claves sobre el papel de las fortalezas en el entramado político de la época de arzobispo de Santiago. Otros temas tratados son las luchas entre el poder real y el eclesiástico ${ }^{39}$ o las expresiones políticas de las ciudades. ${ }^{40}$ López Alsina, a través de la historia urbana, nos acerca al

33 José Miguel Andrade Cernadas "El abad Pedro I de Celanova (1091-1119): una primera aproximación”, en PÉREZ LÓPEZ, S. L.: Plenitudo veritatis: homenaje a Mons. Romero Pose (Santiago de Compostela: Instituto Teológico Compostelano, 2008), 653-664.

${ }^{34}$ José Miguel Andrade Cernadas Alfonso II el Casto (Vigo: NigraTrea, 2009).

${ }^{35}$ Ermelindo Portela Silva, "Tiempos de reforma y espacios de frontera. En torno a los orígenes del monasterio de Santa María de Oia" Revista Chilena de Estudios Medievales, 12 (2017), 625-720.

${ }^{36}$ Ana P. Leite Rodrigues, "O sagrado e o religioso em prol do político. Aspectos da formação do reino de Portugal e da fronteira galego-portuguesa através da documentação do mosteiro de Oia e das Vitae de S. Teotónio e S. Rosendo", en Temporalidad y Contextos. La interdisciplinariedad a partir de la historia, el arte y la lingüística, Israel Sanmartín y Sonia Gómez Jordana (eds.) (Santiago de Compostela, Universidad de Santiago de Compostela, 2015), 511-521.

${ }^{37}$ Paz Romero Portilla, "Fronteras de aire: Portugal, León y Castilla en el siglo XIII", Cuadernos de estudios gallegos, 128 (2015), 47-81.

${ }^{38}$ Ermelindo Portela Silva y María del Carmen Pallares Méndez, "De la función de los castillos en el tiempo y los espacios de Diego Gelmírez", en El historiador y la sociedad: homenaje al profesor José M. ${ }^{a}$ Mínguez, Pablo de La Cruz Díaz Martínez y otros (eds.) (Salamanca: Universidad de Salamanca, 2013), 189-204.

${ }^{39}$ Ermelindo Portela Silva, "El rey y los obispos: Poderes locales en el espacio galaico durante el periodo astur" Symposium Internacional Poder y Simbología en Europa, siglos VIII-X, Francisco Javier Fernández Conde y César García de Castro Valdés (Coords.) (Oviedo: Universidad de Oviedo, 2009), 215-226.

${ }^{40}$ Ermelindo Portela Silva, "Expresiones políticas de la sociedad urbana" en Alfonso VI y su legado: Actas del Congreso Internacional, Sahagún, 29 de octubre al 1 de noviembre de 2009: IX Centenario de Alfonso VI (1109-2009), Carlos Estepa Díez y otros (Coord.) (León: Instituto Leonés de cultura, 2012), 73-79. 
campo político de Santiago de Compostela en la Alta Edad Media, ${ }^{41}$ con la reedición del trabajo publicado en 1987. Las monarquías europeas ocupan un breve espacio en trabajos como el de Ermelindo Portela sobre la expansión de Occidente en el Báltico ${ }^{42}$ o el de José Ángel Salgado sobre el contexto de Otón III. ${ }^{43}$

Por otra parte, Anselmo López Carreira hace una historia de Galicia, desde una perspectiva nacionalista en la búsqueda de la identidad nacional gallega, con monografías como $O$ reino medieval de Galicia: contribución a unha historia política ${ }^{44}$, y "O reino galego dos Suevos". 45

Por lo tanto en este campo de la historia política comprobamos la diversidad de metodologías empleadas y la diversidad de temas. Vemos también que las inquietudes no se refieren solo a Galicia sino que el medievalismo gallego va más allá de este espacio geográfico.

\section{Tendencias historiográficas emergentes}

La historia de las mentalidades y la historia de las mujeres aparecen consolidadas en el período 2007-2017.

\section{La historia de las mentalidades}

La historia de las mentalidades ocupa un lugar secundario en la producción científica del medievalismo gallego. Carlos Barros, uno de los más destacados en Galicia, continúa desarrollando el tema de las revueltas Irmandiñas, en el artículo "Torres, varas e demos: os Irmandiños da ría Muros-Noia"46 Carlos Barros estudia la revuelta en el contexto de una villa costera. Torres, varas e demos representan al poder señorial, la justicia y el señor feudal, respectivamente, las torres por tanto deben ser destruidas para que caiga el poder señorial. Carlos Barros en "Os irmandiños na Terra de Lemos" 47 estudia estas revueltas en el interior de Galicia. La relación entre las revueltas irmandiñas y la Santa Hermandad ${ }^{48}$ también es objeto de estudio de éste

\footnotetext{
${ }^{41}$ Fernando López Alsina, La ciudad de Santiago de Compostela en la Alta Edad Media, (Santiago de Compostela: Consorcio de Santiago Compostela, 2013) (1 ${ }^{\text {a }}$ edición 1988).

${ }^{42}$ Ermelindo Portela Silva, "La expansión de Occidente, el Mar Báltico, el drang nach osten, la cristianización de Escandinavia" en Historia de la Edad Media, Salvador Claramunt y otros (Barcelona: Ariel, 2014), 176-182 ( $1^{a}$ edición 1992).

${ }^{43}$ José Ángel Salgado loureiro, "La sacropolítica de Otón III y la Renovatio Imperii en las cercanías del año mil" en Temporalidad y Contextos. La interdisciplinariedad a partir de la historia, el arte y la lingüística, Israel Sanmartín y Sonia Gómez Jordana (eds.) (Santiago de Compostela: Universidad de Santiago de Compostela, 2015), 523-533.

${ }^{44}$ Anselmo López Carreira, $O$ reino medieval de Galicia: contribución a unha historia política (Vigo: Promocións Culturais Galegas, 2008).

${ }^{45}$ Anselmo López Carreira, "O reino galego dos Suevos (sécs. V-VI)", Murguía, 21-22, (2010), 17-28.

${ }^{46}$ Carlos Barros Guimeráns, Torres, varas e demos: os Irmandiños da ría Muros-Noia (Noia: Toxosoutos, 2009).

${ }^{47}$ Carlos Barros Guimeráns, “Os irmandiños na Terra de Lemos”, en O Condado de Lemos na Idade Media (Santiago de Compostela: Xunta de Galicia, 2008), 195-204.

${ }^{48}$ Carlos Barros Guimeráns, "Los irmandiños. La Santa Hermandad del Reino de Galicia”, Historia de la Iberia Vieja, 22 (2007), 54-59.
} 
investigador. Por su parte, Erias Martínez enfoca la investigación irmandiña a través de Afonso de Carvallido, ${ }^{49}$ uno de sus líderes.

José Miguel Andrade amplía el estudio de los monasterios a la alimentación. ${ }^{50}$ Este mismo investigador estudia la violencia ${ }^{51}$ en la sociedad feudal a través de las fuentes testamentarias. Temas como la vejez, la infancia o la vida cotidiana en los monasterios ocupan varios trabajos de José Miguel Andrade. ${ }^{52}$ La ideología y la cultura medieval son tratadas por García Tato a través de los mitos y su relación con el Camino de Santiago. La función y el espacio en la vida cotidiana que supone el agua, es investigado por Pérez Rodríguez y Vaquero Díaz en "Fuentes y baños en Ourense en la Edad Media". ${ }^{53}$ Otros temas que interesan al medievalismo en el ámbito de la historia de las mentalidades en Galicia son los relacionados con las peregrinaciones y las tradiciones jacobeas, así como las luchas entre caballeros.

\section{La historia de las mujeres}

La historia de las mujeres, que parte del deseo de visibilizar a la población femenina como sujeto histórico, goza de buena salud en la historiografía gallega. Hemos seleccionados varios trabajos que reflejan el interés por estudiar la historia desde una perspectiva de género. Comenzamos por María del Carmen Pallares, quien fue la primera mujer catedrática de Historia Medieval en la Universidad de Santiago de Compostela. Esta investigadora tiene en las historia de las mujeres una de sus líneas de investigación. "Conciencia y resistencia. La denuncia de la agresión masculina en la Edad Media" 54 es la contribución de Carmen Pallares a la monografía Investigaciones actuales de las mujeres y del género, trabajo interdisciplinar vinculado al Centro Interdisciplinario de Investigacións Feministas e de Estudos de Xénero (CIFEX) de la Universidad de Santiago de Compostela. Esta investigadora cuenta con otros trabajos en los que trata temas tan variados como puede ser la vida de las mujeres en el convento,

\footnotetext{
49 Alfredo Erias Martínez "Afonso de Carvallido: a imaxe dun líder irmandiño na Galicia do século XV", Galegos = Gallegos, 5 (2009), 178-179.

${ }^{50}$ José Miguel Andrade Cernadas, "En el refectorio: la alimentación en el mundo monástico de la Galicia medieval", Semata, 21 (2009), 45-64.

${ }^{51}$ José Miguel Andrade Cernadas, "La violencia recordada: confesiones testamentarias en la Galicia de finales de la Edad Media", Semata, 19 (2008), 65-77.

${ }^{52}$ José Miguel Andrade Cernadas, “Asilos monásticos: vejez y mundo cenobítico en el noroeste hispánico entre los siglos IX al XI", Mundos medievales: espacios, sociedades y poder: homenaje al profesor José Ángel García de Cortázar y Ruiz de Aguirre, Vol. 1 (Santander: Universidad de Cantabria, 2012), 311324.

José Miguel Andrade Cernadas.: "Las edades del hombre en los monasterios benedictinos y cistercienses: de la infancia a la vejez" en El ritmo cotidiano de la vida en el monasterio medieval, José Ángel García Cortázar y Ramón Teja (coords.) (Palencia: Centro de Estudios del Románico, 2015), 111-141.

${ }^{53}$ Francisco J. Pérez Rodríguez y María Beatriz Vaquero Díaz, "Fuentes y baños en Ourense en la Edad Media», en Libro de actas del I congreso internacional del agua, Termalismo y calidad de vida. José María Faílde Garrido y otros (ed.) (Ourense: Universidad de Vigo, 2016), 299-306.

${ }^{54}$ María del Carmen Pallares Méndez, "Conciencia y resistencia. La denuncia de la agresión masculina en la Edad Media" en: Investigaciones actuales de las mujeres y del género, Rita Radl Philipp (ed.) (Santiago de Compostela: Universidad de Santiago de Compostela, 2010), 177-198.
} 
trabajo que firma junto con Ermelindo Portela, ${ }^{55}$ o el análisis de la carta de arras que el conde Rodrigo Martínez otorga a su esposa la condesa Urraca. ${ }^{56}$

Marta González en La emperatriz Berengela, ${ }^{57}$ utiliza como método la biografía de grandes personajes femeninos para, a través de ellos, atisbar el mundo en el que vivían dejando constancia de su contribución histórica. Metodología que González Paz utiliza en Guncina González volens ire Iherusalem. ${ }^{58}$ Por último, traemos el trabajo de García Fernández "¿Libertinaje o libertad? Rompiendo la(s) Regla(s) en los monasterios de monjas benedictinas de la Galicia bajomedieval". ${ }^{59}$ Este joven autor es una de las últimas incorporaciones a la historia de la mujer en Galicia.

\section{La estabilización de la historia sociocultural}

La historia social y la cultural se han estabilizado en el período estudiado. Los diferentes investigadores gallegos han seguido insistiendo en las temáticas relacionadas con estos temas.

\section{La historia cultural}

La historia cultural no despierta la atención del medievalismo gallego. No son muchos los trabajos publicados en estos diez años, a pesar de que sí ha sido el tema de una tesis doctoral que no se ha publicado como tal. ${ }^{60}$ Comenzamos destacando el trabajo del medievalista José Miguel Andrade que pone la atención en las escuelas y bibliotecas en la Edad Media ${ }^{61}$ y en el monacato como espacio cultural. Este mismo autor en "Cultura clerical y cultura popular en el legendario jacobeo: la barca de piedra" $" 62$ estudia las imbricaciones entre las culturas popular y clerical a través de la tradición de la barca de piedra que condujo al Apóstol Santiago de Tierra Santa a Galicia. Por último, Fernández estudia el lenguaje medieval en el cancionero de Ajuda. $^{63}$

\footnotetext{
${ }^{55}$ María del Carmen Pallares Méndez y Ermelindo Portela Silva "Las señoras en el claustro" en Mundos medievales: espacios, sociedades y poder: homenaje al profesor José Ángel García de Cortázar y Ruiz de Aguirre, Vol. 1, (Santander: Universidad de Cantabria, 2012), 173-186.

${ }^{56}$ María del Carmen Pallares Méndez, "La mujer y la serpiente. A propósito de la carta de arras de la condesa doña Urraca Fernández”, Edad Media: revista de historia, 18 (2017), 240-262.

${ }^{57}$ Marta González Vázquez, La emperatriz Berenguela (Vigo: NigraTrea, 2008).

${ }^{58}$ Carlos Andrés González Paz, "Guncina González volens ire Iherusalem", en Women and Pilgrimage in Medieval Galicia, Carlos Andrés González Paz (ed.) (London \& New York: Routledge, 2016), 51-63.

${ }^{59}$ Miguel García Frenandez, "¿Libertinaje o libertad? Rompiendo la(s) Regla(s) en los monasterios de monjas benedictinas de la Galicia bajomedieval" en Universos en orden, vol. I, José M. García Iglesias (ed.), (Santiago de Compostela: Alvarellos Editora, 2014), 121-152.

60 Juan Coira Pociña, J.: A cultura popular na Galicia medieval: ocio e devocións (Santiago de Compostela: Universidad de Santiago de Compostela, 2016).

${ }^{61}$ José Miguel Andrade Cernadas, "Claustros y vida cultural en la Edad Media. Escuelas y bibliotecas en la Edad Media”, en El protagonismo monástico a través de la historia, José Miguel Andrade Cernadas, et al., Vol. 1 (A Coruña: Hércules de Ediciones, 2016), 299-309.

${ }^{62}$ José Miguel Andrade Cernadas, "Cultura clerical y cultura popular en el legendario jacobeo: la barca de piedra”, El Extramundi y los papeles de Iria Flavia, 63 (2010), 115-124.

63 Antonio Fernández Guiadanes, "Uso y funciones de la plica en el Cancionero da Ajuda: identificación del Usus Scribendi de los copistas", en La materialidad escrita: nuevos enfoques para su interpretación, Manuel Salamanca López (dir.) (Oviedo: Instituto de Estudios para la Paz y la Cooperación, 2011), 48107.
} 


\section{La historia religiosa cultural}

La religiosidad popular, la historia monástica o las relaciones entre el poder real y el eclesiástico atraen el interés del medievalismo gallego. La historia religiosa tiene en José García Oro a uno de los máximos representantes y su arco temporal prioritario abarca los siglos XV y XVI. Traemos dos de los trabajos publicados por García: "Francisco de Asís en Compostela. Aspectos de una tradición franciscana" 64 y "Los Frailes Menores en la Hispania medieval y su asentamiento". ${ }^{65}$ En el primero estudia la tradición que sitúa a Francisco de Asís en Santiago como peregrino, en el segundo trabajo continúa con los franciscanos pero ahora poniendo la atención en los frailes menores, la rama más numerosa de la Orden de San Francisco de Asís.

José Miguel Andrade en "La introducción de Cluny en Galicia: ritmos y resistencias", ${ }^{66}$ estudia la introducción de la abadía en Galicia aportando elementos nuevos como la adhesión del monacato gallego a la regla de Cluny. García Tato y Piñeyro Maseda en su artículo "Asentamiento, desarrollo y ocaso de la Orden del Santo Sepulcro en Galicia. Un panorama y un documento singular" ${ }^{\text {,7 }}$ repasan la historia de la Orden de Santo Sepulcro en Galicia. La función que cumple en la Edad Media el pensamiento teológico es también estudiado por García Tato. ${ }^{68}$ Dolores Fraga y Mari Luz Ríos ponen el foco en la devoción por la Virgen María en Santiago en su artículo "Aproximación a la topografía espiritual de Santiago en la Baja Edad Media: antiguas y nuevas devociones". 69

Por último traemos el artículo firmado por María del Carmen Pallares y Ermelindo Portela sobre Cadaval y la implantación del Cister en Galicia: Bernardo de Claraval y la implantación cisterciense en Galicia. ${ }^{70}$ Sirvan estos trabajos como muestra del interés por estos temas por parte del medievalismo gallego.

\section{La historia social}

Para la historia social hemos extraído varios trabajos que nos pueden indicar las inquietudes y los vacíos de la investigación en la historia social de Galicia. Como hemos indicado más arriba, las líneas de investigación de Eduardo Pardo de Guevara se centran en el espacio temporal de la baja Edad Media y de forma más concreta en la

64 José García Oro, "Francisco de Asís en Compostela. Aspectos de una tradición franciscana" Compostellanum, 57, 3-4, (2012), 143-154.

65 José García Oro, "Los Frailes Menores en la Hispania medieval y su asentamiento" Archivo IberoAmericano, 73, 275-276 (2013), 195-228.

${ }^{66}$ José Miguel Andrade Cernadas, "La introducción de Cluny en Galicia: ritmos y resistencias" Studia monastica, 57, 1 (2015), 91-109.

${ }^{67}$ Isidro García Tato y Pablo Otero Piñeyro Maseda, "Asentamiento, desarrollo y ocaso de la Orden del Santo Sepulcro en Galicia. Un panorama y un documento singular", Cuadernos de Estudios Gallegos, 59 (2012), 65-94.

68 Isidro García Tato, "La función del pensamiento teológico en la edad media", Compostellanum, 56 (2011), 861-873.

69 Dolores Fraga Sampedro y María Luz Ríos Rodríguez, “Aproximación a la topografía espiritual de Santiago en la Baja Edhaad Media: antiguas y nuevas devociones”, Ad limina, 5 (2014), 43-62.

${ }^{70}$ María del Carmen Pallares Méndez y Ermelindo Portela Silva, "Bernardo de Claraval y la implantación cisterciense en Galicia", en De Cister a Portugal: o tempo o(s) modo(s): Livro do XI Encontro Cultural de São Cristovão de Lafões, María A. Fernandes Marques y Carlos Luis Amaral (eds.), (São Cristóvão de Lafões: Associação dos Amigos do Mosteiro de São Cristovão de Lafões, 2016), 15-32. 
historia social del poder, además de genealogía y heráldica. En la monografía: De linajes, parentelas y grupos de poder: aportaciones a la historia social de la nobleza bajomedieval gallega y el artículo "La huella de los primeros Ulloa en las torres y fortalezas de la terra de Ulloa"72 Guevara hace un análisis sobre los linajes y el poder señorial; en el segundo artículo se adentra en los orígenes de la familia Ulloa y la edificación de las fortalezas que fueron el símbolo del poder y su importancia en la estructuración social política y económica del mundo agrario.

Carlos Barros en el artículo "Origen del castillo y coto de Aranga, siglos XXII", ${ }^{73}$ señala que una de las funciones que las fortalezas altomedievales cumplían era la vertebración del territorio como jurisdicciones feudales. Barros estudia el traspaso de la jurisdicción que ejercía a este castillo al monasterio de Sobrado y las consecuencias sociales que conllevó.

El estudio de la minoría judía en la Galicia medieval nos llega desde el IEGPS, a través de la monografía publicada por Gloria De Antonio: Judíos y conversos. Relaciones de poder en Galicia y en los reinos hispanos. ${ }^{74}$ Esta investigadora tiene como línea de trabajo a la comunidad judía en Galicia. Ha publicado varios trabajos en los que trata de la demografía, los personajes o el espacio geográfico que habitaron. ${ }^{75}$

\section{Los márgenes de la historiografía inmediata en el medievalismo gallego}

Otras tendencias minoritarias y con una importancia menor son las relativas a la historia intelectual y la historiografía.

\section{La historia intelectual}

Hemos llamado historia intelectual a aquella que se ocupa de estudiar los textos medievales intentando desentrañar el pensamiento de sus autores, de tratar de ver el mundo medieval a través de sus escritos. En ellos se aprecia las cuestiones que recorren la sociedad de su tiempo, cómo perciben y sienten el mundo. Aunque son pocos los medievalistas que trabajan en este campo de la historia y en el total de la historiografía apenas ocupa una pequeña parte, nos parece interesante resaltarla porque contribuye al mejor conocimiento de la sociedad medieval y, también, por lo que supone de renovación metodológica. Todo bajo una influencia francesa y anglosajona.

Ángel Salgado, en su trabajo, "La revolución sin revolución en la teoría política pleno-medieval: el tiranicidio y la ausencia de acción colectiva en el Policraticus"76

\footnotetext{
${ }^{71}$ Eduardo Pardo de Guevara, De linajes, parentelas y grupos de poder: aportaciones a la historia social de la nobleza bajomedieval gallega, (Madrid: Fundación Cultural de la Nobleza Española, 2012).

72 Eduardo Pardo de Guevara, Pablo Otero Piñeyro Maseda y Xosé Antón García González Ledo, "La huella de los primeros Ulloa en las torres y fortalezas de la tierra de Ulloa", Castillos de España, 164-166 (2012), 59-67.

${ }^{73}$ Carlos Barros Guimeráns, "Origen del castillo y coto de Aranga, siglos X-XII: The origin of the castle and the jurisdiction of Aranga, X-XII centuries”, Cuadernos de estudios gallegos, 122 (2009), 139-150.

${ }^{74}$ Eduardo Pardo de Guevara y Gloria de Antonio Rubio (eds.): Judios y conversos. Relaciones de poder en Galicia y en los reinos hispanos (Santiago de Compostela: CSIC, 2017).

${ }^{75}$ Gloria de Antonio Rubio, "Judíos y juderías en la Galicia medieval”, Minius, 20 (2012), 7-28 y Gloria de Antonio Rubio, Los judios en Galicia (1044-1492) (A Coruña: Pedro Barrié de la Maza, 2007).

${ }^{76}$ Jose Ángel Salgado Loureiro, "La revolución sin revolución en la teoría política pleno-medieval: el tiranicidio y la ausencia de acción colectiva en el Policraticus”, Semata, 28, (2016), 225-244.
} 
plantea la hipótesis de que el tiranicidio en la obra de John de Salisbury lleva implícita una teoría proto-revolucionaria de oposición al poder legítimo. Esta cuestión pondría en cuestión la ausencia de teorías revolucionarias en época pleno-medieval.

Israel Sanmartín en Imágenes y apocaliptismo en el occidente medieval ${ }^{77}$ busca el espacio de convergencia entre el apocaliptismo y las imágenes para concluir la importancia de la localización de éstas para hacer presente lo ausente. Sanmartín continúa indagando en el apocaliptismo en el artículo "El pensamiento del año mil en el franciscanismo apocalíptico,, 78 en este texto estudia la capacidad transformadora del franciscanismo Joaquinita con el fin de matizar la idea de los autores del siglo XIII sobre el siglo XI. El texto Raúl de Glaber Historias del primer milenio, escrito en el siglo XI, es para algunos autores el reflejo de la psicología colectiva y la mentalidad de su tiempo. Sanmartín estudia en el artículo Temporalidad y contexto en la historiografía del siglo $X^{79}$ a partir de Raúl Glaber la dicotomía realidad-ficción en un texto inserto en la sociedad de su tiempo en la que salvación y juicio final están muy presentes.

\section{La historiografía}

La historiografía medievalista en Galicia es poco estudiada y son pocos los investigadores que la trabajan. Destaca Israel Sanmartín con una amplia producción historiográfica que sobrepasa lo medieval. Hemos elegido dos artículos, en "Las órdenes religiosas y las ideas: el concepto de año 1000 en tres ejemplos historiográficos del siglo XIV"80 y "La cultura histórica sobre el 'año mil' en sus diferentes historiografías $^{81}$ en los que examina distintos textos y, a la vez, la historiografía referente al concepto del año Mil. Por otra parte, Álvaro Solano realiza un estudio historiográfico sobre la historia urbana en "Historia urbana en la Galicia medieval. Balance y perspectivas". 82 Pérez Rodríguez hace un estudio historiográfico del medievalismo gallego en "Historia Medieval de Galicia: un balance historiográfico $(1988-2008) " .83$

\section{La hegemonía de la organización social del territorio y de la historia política}

Retomando el concepto de "campo" de Bourdieu, y por lo expuesto en estas líneas en las que hemos hecho referencia a los trabajos publicados en Galicia en el período 2007-2017, dentro del campo de la Historiografía medieval en Galicia es hegemónico la

\footnotetext{
${ }^{77}$ Israel Sanmartín Barros, "Imágenes y apocaliptismo en el occidente medieval", Cuadernos de estudios gallegos, 124 (2011), 11-28.

${ }_{78}$ Israel Sanmartín Barros, "El pensamiento del año mil en el franciscanismo apocalíptico", Semata, 26 (2014), 343-358.

${ }^{79}$ Israel Sanmartín Barros, "Temporalidad y contexto en la historiografía del siglo XI a partir de Raúl Glaber" en Temporalidad y contextos: la interdisciplinariedad a partir de la historia, el arte y la lingüística, Israel Sanmartín y Sonia Gómez Jordana (eds.), (Santiago de Compostela: Servicio de Publicaciones de la Universidad de Santiago de Compostela, 2015), 335-360.

${ }^{80}$ Israel Sanmartín Barros, "Las órdenes religiosas y la heterodoxia: el concepto de año mil en Margarita de Porete" en Universos en orden, vol. I, José M. García Iglesias (ed.), (Santiago de Compostela: Alvarellos Editora, 2014), 1321-1345.

${ }^{81}$ Israel Sanmartín Barros, "La cultura histórica sobre el «año mil» en sus diferentes historiografías", Revista de História das Ideias. Vol. 34 (2016), 87-111.

82 Álvaro Solano Fernández-Sordo, "Historia urbana en la Galicia medieval. Balance y perspectivas", Cuadernos de Estudios Gallegos, 123 (2010), 55-90.

${ }^{83}$ José Pérez Rodríguez, "Historia Medieval de Galicia: un balance historiográfico (1988-2008)", Minius, 18 (2010), 59-146.
} 
organización social del territorio (ver gráfico). Es la que se encuentra más desarrollada $\mathrm{y}$, sin duda la que acapara la atención de un mayor número de los medievalistas gallegos. Le sigue la historia política, con la biografía política como una de las metodologías desarrolladas. Los análisis de frontera, el Reino de Galicia y lo relacionado con el poder real y el arzobispo de Santiago son los temas más recurrentes.

La producción científica de la historia de las mentalidades ocupa un tercer lugar, en este ámbito de estudio, los trabajos sobre los irmandiños y la nobleza centran la atención, con menor número de trabajos dedicados a la población campesina. Mientras que la historia de la mujer creemos que tiene suficiente fuerza, la historia cultural se encuentra poco tratada por los medievalistas. Por otro lado, el estudio historiográfico y la historia intelectual están en los márgenes del campo.

Nos queda por tratar la transcripción documental que continúa a un ritmo lento con pocos investigadores que tengan esta línea de estudio de forma prioritaria. Debemos destacar la labor realizada por el Centro Ramón Piñeiro con el proyecto Corpus Documentale Latinum Gallaeciae (CODOLGA) ${ }^{84}$ en la edición de fuentes documentales. Ya hemos mencionado, la producción de heráldica y genealogía que desde el Instituto de Estudios Gallegos lleva años realizando Eduardo Pardo Ladrón de Guevara. En cuanto a la historia urbana solo hemos encontrado dos artículos que hemos incluido en la historia política por el enfoque de los estudios realizados.

Pensamos que la investigación medievalista gallega está plenamente inserta en su entorno, con intercambios y estancias de docentes en universidades españolas y extranjeras, entre estas últimas se encuentran las de Lisboa, Porto, Reino Unido o Estados Unidos. La realización de congresos y el intercambio científico es la norma. Aun así las dificultades en ocasiones se dejan notar.

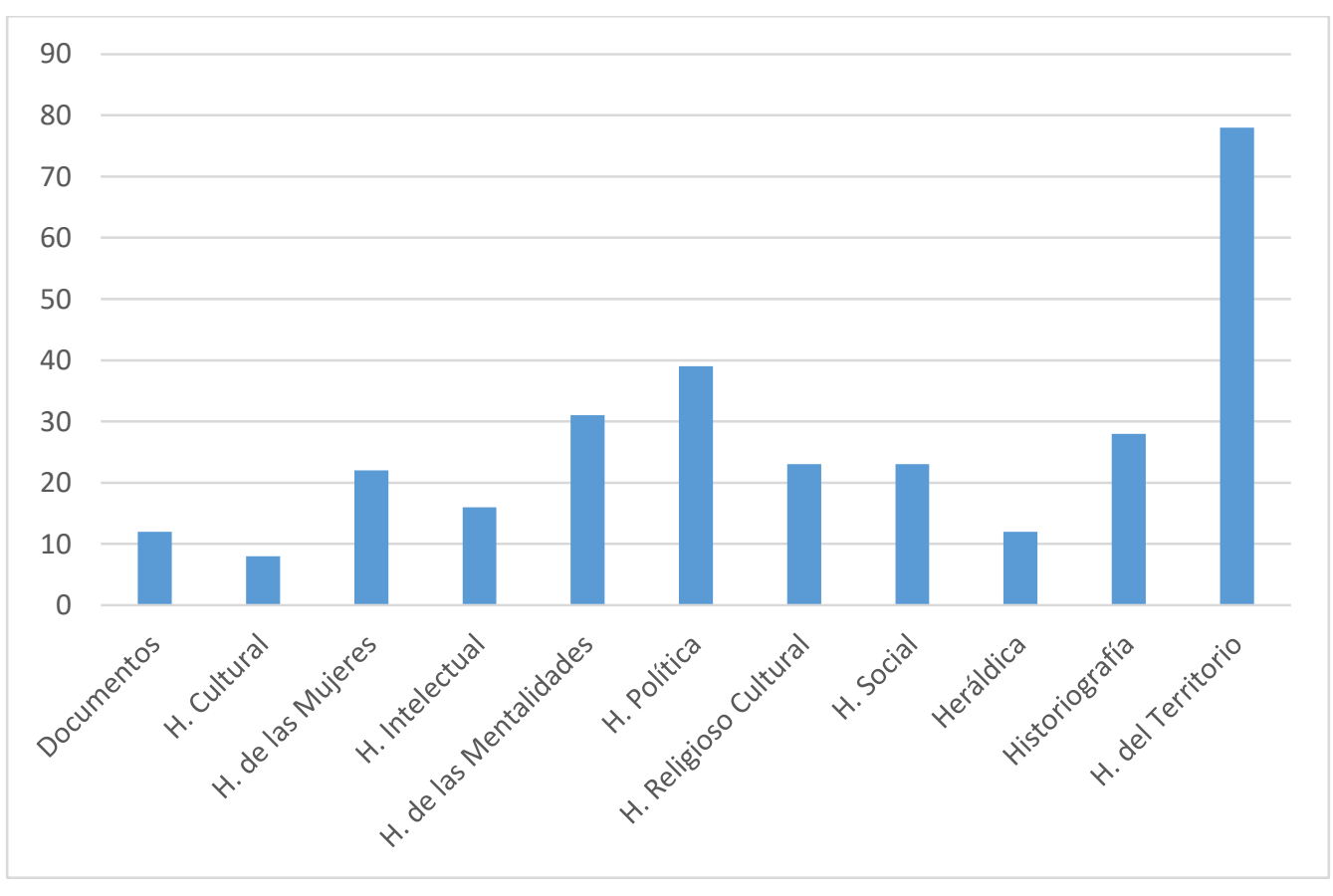

84 "CODOLGA: Corpus Documentale Latinum Gallaeciae", corpus.cirp.gal , <http://corpus.cirp.gal/codolga>, [Consultado el 31 de mayo de 2019] 
Gráfico de la producción historiográfica en Galicia en el período 2007-2017

\section{Bibliografía}

José Miguel Andrade Cernadas, Las transformaciones de la sociedad gallega en los siglos XI al XIII: el papel de los monjes negros, tesis doctoral (Santiago de Compostela: Universidad Santiago de Compostela, 1993.

José Miguel Andrade Cernadas "El abad Pedro I de Celanova (1091-1119): una primera aproximación", en PÉREZ LÓPEZ, S. L.: Plenitudo veritatis: homenaje a Mons. Romero Pose (Santiago de Compostela: Instituto Teológico Compostelano, 2008), 653664.

José Miguel Andrade Cernadas, "La violencia recordada: confesiones testamentarias en la Galicia de finales de la Edad Media”, Semata, 19 (2008): 65-77.

José Miguel Andrade Cernadas Alfonso II el Casto (Vigo: NigraTrea, 2009).

José Miguel Andrade Cernadas, "En el refectorio: la alimentación en el mundo monástico de la Galicia medieval", Semata, 21 (2009): 45-64.

José Miguel Andrade Cernadas, "Cultura clerical y cultura popular en el legendario jacobeo: la barca de piedra", El Extramundi y los papeles de Iria Flavia, 63 (2010): 115-124.

José Miguel Andrade Cernadas, "Asilos monásticos: vejez y mundo cenobítico en el noroeste hispánico entre los siglos IX al XI", Mundos medievales: espacios, sociedades y poder: homenaje al profesor José Ángel García de Cortázar y Ruiz de Aguirre, Vol. 1 (Santander: Universidad de Cantabria, 2012), 311-324.

José Miguel Andrade Cernadas.: "Las edades del hombre en los monasterios benedictinos y cistercienses: de la infancia a la vejez" en El ritmo cotidiano de la vida en el monasterio medieval (Palencia: Centro de Estudios del Románico, 2015), 111-141.

José Miguel Andrade Cernadas, "La introducción de Cluny en Galicia: ritmos y resistencias" Studia monastica, 57, 1 (2015): 91-109.

José Miguel Andrade Cernadas, "El protagonismo de monasterios y conventos en la agricultura y el mundo rural gallego a lo largo de la historia. Monasterios y conventos gallegos en la Edad Media: su influencia en la agricultura y en el mundo rural", en $E l$ protagonismo monástico a través de la historia fotografía (La Coruña: Ediciones Hércules, 2016), 113-149.

José Miguel Andrade Cernadas, "Claustros y vida cultural en la Edad Media. Escuelas y bibliotecas en la Edad Media", en El protagonismo monástico a través de la historia (La Coruña: Hércules de Ediciones, 2016), 299-309. 
Carlos Baliñas Pérez, Do mito á realidade: a definición social e territorial de Galicia na Alta Idade Media (séculos VIII e IX) (Santiago de Compostela: Universidad Santiago de Compostela, 1990).

Carlos Barros Guimares, Mentalidad y revuelta en la Galicia irmandiña: favorables y contrarios, tesis doctoral, Universidad Santiago de Compostela, 1989.

Carlos Barros Guimerans, Xudeus e conversos na historia. Actas do Congreso Internacional, Ribadavia 14-17 de outubro de 1991 (Santiago de Compostela, 1994).

Carlos Barros Guimerans, Historia a Debate: Medieval (Santiago de Compostela: Xunta de Galicia, 1995).

Carlos Barros Guimeráns, "Los irmandiños. La Santa Hermandad del Reino de Galicia", Historia de la Iberia Vieja, 22 (2007): 54-59.

Carlos Barros Guimeráns, "Os irmandiños na Terra de Lemos", en $O$ Condado de Lemos na Idade Media (Santiago de Compostela: Xunta de Galicia, 2008), 195-204.

Carlos Barros Guimeráns, Torres, varas e demos: os Irmandiños da ría Muros-Noia (Noia: Toxosoutos, 2009).

Carlos Barros Guimeráns, "Origen del castillo y coto de Aranga, siglos X-XII: The origin of the castle and the jurisdiction of Aranga, X-XII centuries", Cuadernos de estudios gallegos, 122 (2009): 139-150.

Pierre Bourdieu, El oficio de científico (Barcelona: Anagrama, 2003), 17-40.

Juan Coira Pociña, J.: A cultura popular na Galicia medieval: ocio e devocións (Santiago de Compostela: Universidad de Santiago de Compostela, 2016).

Gloria de Antonio Rubio, “Judíos y juderías en la Galicia medieval”, Minius, 20 (2012), 7-28 y Gloria de Antonio Rubio, Los judios en Galicia (1044-1492) (La Coruña: Pedro Barrié de la Maza, 2007).

Mercedes Durany Castillo, La región del Bierzo desde finales del siglo IX hasta mediados el siglo XIII el proceso de ocupación y organización social del espacio (Santiago de Compostela: Universidad de Santiago de Compostela, 1987).

Mercedes Durany Castrillo, "El espacio berciano en la Edad Media, punto de partida y escenario de nuestras investigaciones", en Mundos medievales: espacios, sociedades y poder: homenaje al profesor José Ángel García de Cortázar y Ruiz de Aguirre, Vol. 1, (Santander: Universidad de Cantabria, 2012), 105-118.

Alfredo Erias Martínez "Afonso de Carvallido: a imaxe dun líder irmandiño na Galicia do século XV”, Galegos = Gallegos, 5 (2009): 178-179.

Antonio Fernández Guiadanes, "Uso y funciones de la plica en el Cancionero da Ajuda: identificación del Usus Scribendi de los copistas", en La materialidad escrita: nuevos 
enfoques para su interpretación, Manuel Salamanca López (dir.) (Oviedo: Instituto de Estudios para la Paz y la Cooperación, 2011), 48-107.

Elisa Ferreira Prieguez, E. M.: Galicia en el comercio marítimo medieval (Santiago de Compostela: Universidad Santiago de Compostela, 1986).

Dolores Fraga Sampedro y María Luz Ríos Rodríguez, "Aproximación a la topografía espiritual de Santiago en la Baja Edad Media: antiguas y nuevas devociones", Ad limina, 5 (2014): 43-62.

José Ángel García de Cortázar y Ruíz de Aguirre, El dominio del Monasterio de San Millán de la Cogolla (siglos X-XIII). Introducción a la historia rural de Castilla altomedieval (Salamanca: Universidad de Salamanca, 1969).

José Ángel García de Cortázar y Ruíz de Aguirre, "La economía rural medieval: un esquema de análisis histórico de base regional", en Actas de las I jornadas de Metodología Aplicada a las Ciencias Históricas. Vol II. Historia Medieval, (Universidad de Santiago de Compostela, 1975).

José A. García de Cortázar y Ruíz de Aguirre, La economía rural medieval: un esquema de análisis estructural de sus contenidos a través del ejemplo hispano-cristiano, (Universidad de Santander, 1978).

Miguel García Fernández, "¿Libertinaje o libertad? Rompiendo la(s) Regla(s) en los monasterios de monjas benedictinas de la Galicia bajomedieval" en Universos en orden, (Santiago de Compostela: Alvarellos Editora, 2014), 121-152.

José García Oro, "Francisco de Asís en Compostela. Aspectos de una tradición franciscana" Compostellanum, 57, 3-4, (2012): 143-154.

José García Oro, "Los Frailes Menores en la Hispania medieval y su asentamiento" Archivo Ibero-Americano, 73, 275-276 (2013): 195-228.

Isidro García Tato, "La función del pensamiento teológico en la edad media", Compostellanum, 56 (2011): 861-873.

Isidro García Tato y Pablo Otero Piñeyro Maseda, "Asentamiento, desarrollo y ocaso de la Orden del Santo Sepulcro en Galicia. Un panorama y un documento singular", Cuadernos de Estudios Gallegos, 59 (2012): 65-94.

Carlos Andrés González Paz, Cardim, P. y Luís Adão da Fonseca, "Fronteira/fronteiras e identidade", en Luís Adão da Fonseca (coord.), Entre Portugal e a Galiza (sécs. XI a XVII). Um olhar peninsular sobre uma região histórica, (Porto, Fronteira do Caos ed., CEPESE, 2014), 231-251.

Carlos Andrés González Paz, "Guncina González volens ire Iherusalem”, en Women and Pilgrimage in Medieval Galicia (London \& New York: Routledge, 2016), 51-63.

Marta González Vázquez, La emperatriz Berenguela (Vigo: NigraTrea, 2008). 
Amancio Isla Frez, La sociedad gallega en la alta edad media (Madrid: Consejo Superior de Investigaciones Científicas, 1992).

Ana P. Leite Rodrigues, Senhores e camponeses num espaço de fronteira: estudo da projecçao portuguesa do domínio monástico de Santa Maria de Oia nos séculos XII a $X V$, (Tesis doctoral, Santiago de Compostela, 2014).

Ana P. Leite Rodrigues, "O sagrado e o religioso em prol do político. Aspectos da formação do reino de Portugal e da fronteira galego-portuguesa através da documentação do mosteiro de Oia e das Vitae de S. Teotónio e S. Rosendo", en Temporalidad y Contextos. La interdisciplinariedad a partir de la historia, el arte y la lingüística, Israel Sanmartín y Sonia Gómez Jordana (eds.) (Santiago de Compostela: Universidad de Santiago de Compostela, 2015), 511-521.

Fernando López Alsina, La ciudad de Santiago de Compostela en la Alta Edad Media (años 800-1150) (Santiago de Compostela: Universidad Santiago de Compostela, 2013).

Fernando López Alsina, "La articulación de las unidades de organización social del espacio en Galicia durante la Edad Media: Villa, Parroquia, Terra", en La pervivencia del concepto: nuevas reflexiones sobre la ordenación social del espacio en la Edad Media (Zaragoza: Universidad de Zaragoza, 2008), 76-84.

Fernando López Alsina, "Da protoparroquia ou parroquia antiga altomedieval á parroquia clásica en Galicia", en A Parroquia en Galicia: pasado, presente e futuro (Santiago de Compostela: Xunta de Galicia, 2009), 57-75.

Fernando López Alsina, La ciudad de Santiago de Compostela en la Alta Edad Media, (Santiago de Compostela: Consorcio de Santiago Compostela, 2013).

Anselmo López Carreira, A Cidade de Ourense no século XV: sociedade urbana na Galicia baixomedieval (Santiago de Compostela: Universidad Santiago de Compostela, 1994).

Anselmo López Carreira, O reino medieval de Galicia: contribución a unha historia política (Vigo: Promocións Culturais Galegas, 2008).

Anselmo López Carreira, "Os Castro: unha alternativa atlantista na Galicia do s. XIV", O Condado de Lemos na Idade Media, (Santiago de Compostela: Consellería de Innovación e Industria, 2008), 57-80.

Anselmo López Carreira, "O reino galego dos Suevos (sécs. V-VI)", Murguía, 21-22, (2010): 17-28.

Faustino Martínez Martínez, "Empleo del lenguaje feudal como lenguaje amoroso: el ejemplo del Cancioneiro de Ajuda", Cuaderno de Estudios Gallegos, [vol.] 54, nº 120, (2007): 135-170.

María del Carmen Pallares Méndez, Estructura y evolución del dominio del Monasterio de Sobrado en la Edad Media (900-1300) (Santiago de Compostela: Universidad de Santiago de Compostela, 1977). 
María del Carmen Pallares Méndez y Ermelindo Portela Silva, "Historiografía sobre la edad media de Galicia en los diez últimos años (1976-1986)", Studia historica. Historia medieval, 6 (1988): 7-26.

María del Carmen Pallares Méndez, Vida das mulleres na Galicia medieval: 1100-1500 (Santiago de Compostela: Universidad de Santiago de Compostela, 1993).

María del Carmen Pallares Méndez y Ermelindo Portela Silva, "La reina Urraca y el obispo Gelmírez: Nabot contra Jezabel", en da Fonseca, L. Adao, Amaral, L. E Santos, M.F. Ferreira (coords.), Os reinos ibéricos na Idade Média. Livro Homenagem ao Professor Doutor Humberto Carlos Baquero Moreno (Oporto: Livraria Civilização: 2003), 975-962.

María del Carmen Pallares Méndez y Ermelindo Portela Silva, "El lugar de los campesinos. De repobladores a repoblados", en El lugar del campesino: en torno a la obra de Reyna Pastor, (Valencia: CSIC, Universidad de Valencia, 2007), 61-88.

María del Carmen Pallares Méndez, "Conciencia y resistencia. La denuncia de la agresión masculina en la Edad Media" en Investigaciones actuales de las mujeres y del género (Santiago de Compostela: Universidad de Santiago de Compostela, 2010), 177198.

María del Carmen Pallares Méndez, "La mujer y la serpiente. A propósito de la carta de arras de la condesa doña Urraca Fernández", Edad Media: revista de historia, 18 (2017): 240-262.

María del Carmen Pallares Méndez y Ermelindo Portela Silva "Las señoras en el claustro" en Mundos medievales: espacios, sociedades y poder: homenaje al profesor José Ángel García de Cortázar y Ruiz de Aguirre (Santander: Universidad de Cantabria, 2012), 173-186.

María del Carmen Pallares Mendez y Ermelindo Portela Silva, "Bernardo de Claraval y la implantación cisterciense en Galicia", en De Cister a Portugal: o tempo o(s) modo(s): Livro do XI Encontro Cultural de São Cristovão de Lafões, (São Cristóvão de Lafões: Associação dos Amigos do Mosteiro de São Cristovão de Lafões, 2016), 15-32.

Eduardo Pardo de Guevara, Pablo Otero Piñeyro Maseda y Xosé Antón García González Ledo, "La huella de los primeros Ulloa en las torres y fortalezas de la tierra de Ulloa”, Castillos de España, 164-166 (2012): 59-67.

Eduardo Pardo de Guevara, De linajes, parentelas y grupos de poder: aportaciones a la historia social de la nobleza bajomedieval gallega, (Madrid: Fundación Cultural de la Nobleza Española, 2012).

Eduardo Pardo de Guevara y Gloria de Antonio Rubio (eds.): Judíos y conversos. Relaciones de poder en Galicia y en los reinos hispanos (Santiago de Compostela: CSIC, 2017).

Francisco J. Pérez Rodríguez y María Beatriz Vaquero Díaz, "Fuentes y baños en Ourense en la Edad Media», en Libro de actas del I congreso internacional del agua, Termalismo y calidad de vida (Orense: Universidad de Vigo, 2016), 299-306. 
José Pérez Rodríguez, "Historia Medieval de Galicia: un balance historiográfico (19882008)", Minius, 18 (2010): 59-146.

Ermelindo Portela Silva, La región del Obispado de Tuy en los siglos XII al XV. Una sociedad en la expansión y en la crisis, (Santiago de Compostela: Universidad de Santiago de Compostela, 1972).

Ermelindo Portela Silva, "Galicia en la época de Alfonso III" en La época de Alfonso III y San Salvador de Valdediós: Congreso de Historia Medieval Oviedo (Oviedo: Universidad de Oviedo, 1994), 79-96.

Ermelindo Portela Silva, García II de Galicia. El Rey y el Reino (1065-1090) (Burgos: La Olmeda, 2001).

Ermelindo Portela Silva, "Galicia y los reyes de Oviedo", en La época de la Monarquía Asturiana: actas del simposio celebrado en Covadonga (Oviedo: Real Instituto de Estudios Asturianos, 2002), 351-366.

Ermelindo Portela Silva, "El rey y los obispos: Poderes locales en el espacio galaico durante el periodo astur" Symposium Internacional Poder y Simbología en Europa, siglos VIII-X (Oviedo:Universidad de Oviedo, 2009), 215-226.

Ermelindo Portela Silva, "Expresiones políticas de la sociedad urbana" en Alfonso VI y su legado: Actas del Congreso Internacional, Sahagún, 29 de octubre al 1 de noviembre de 2009: IX Centenario de Alfonso VI (1109-2009) (León: Instituto Leonés de cultura, 2012), 73-79.

Ermelindo Portela Silva y María del Carmen Pallares Méndez, "De la función de los castillos en el tiempo y los espacios de Diego Gelmírez", en El historiador y la sociedad: homenaje al profesor José María Mínguez (Salamanca: Universidad de Salamanca, 2013), 189-204.

Ermelindo Portela Silva, "La expansión de Occidente, el Mar Báltico, el drang nach osten, la cristianización de Escandinavia" en Historia de la Edad Media (Barcelona: Ariel, 2014): 176-182.

Ermelindo Portela Silva, "Diego Gelmírez y el trono de Hispania: la coronación real del año 1111” (Santiago de Compostela: Consello da Cultura Galega, 2013), 45-75.

Ermelindo Portela Silva, "Tiempos de reforma y espacios de frontera. En torno a los orígenes del monasterio de Santa María de Oia" Revista Chilena de Estudios Medievales, 12 (2017): 625-720.

Ermelindo Portela Silva, "Diego Gelmírez (c.1065-1140). El báculo y la ballesta", La aventura de la Historia, 223 (2017): 20-23.

María Luz Ríos Rodríguez, Relaciones contractuales agrarias en la Galicia medieval: los orígenes del foro (1150-1350) (Santiago de Compostela: Universidad Santiago de Compostela, 1990). 
María Luz Ríos Rodríguez, Orixes do foro na Galicia Medieval (Santiago de Compostela: Universidad de Santiago de Compostela, 1993).

María Luz Ríos Rodríguez, "Apropiación y organización social de un medio natural: pesca fluvial y pesqueras en la Galicia medieval", en Mundos medievales: espacios, sociedades y poder: homenaje al profesor José Ángel García de Cortázar y Ruiz de Aguirre (Santander: Universidad de Cantabria, 2012), 1827-1842.

Paz Romero Portilla, "Fronteras de aire: Portugal, León y Castilla en el siglo XIII", Cuadernos de estudios gallegos, 128 (2015): 47-81.

José Ángel Salgado loureiro, "La sacropolítica de Otón III y la Renovatio Imperii en las cercanías del año mil" en Temporalidad y Contextos. La interdisciplinariedad a partir de la historia, el arte y la lingüística (Santiago de Compostela: Universidad de Santiago de Compostela, 2015), 523-533.

Jose Ángel Salgado Loureiro, “La revolución sin revolución en la teoría política plenomedieva: el tiranicidio y la ausencia de acción colectiva en el Policraticus", Semata, 28, (2016): 225-244.

Israel Sanmartín Barros, "Historia a Debate como una comunidad científica de historiadores críticos en red (1993-2004)", en Historia a debate: actas del III Congreso Internacional "Historia a Debate" (Santiago de Compostela: Historia a Debate, 2004), 265-284.

Israel Sanmartín Barros, "Imágenes y apocaliptismo en el occidente medieval", Cuadernos de estudios gallegos, 124 (2011): 11-28.

Israel Sanmartín Barros, "El pensamiento del año mil en el franciscanismo apocalíptico", Semata, 26 (2014): 343-358.

Israel Sanmartín Barros, "Las órdenes religiosas y la heterodoxia: el concepto de año mil en Margarita de Porete" en Universos en orden (Santiago de Compostela:Alvarellos Editora, 2014), 1321-1345.

Israel Sanmartín Barros, "Temporalidad y contexto en la historiografía del siglo XI a partir de Raúl Glaber" en Temporalidad y contextos: la interdisciplinariedad a partir de la historia, el arte y la lingüística (Santiago de Compostela: Servicio de Publicaciones de la Universidad de Santiago de Compostela, 2015), 335-360.

Israel Sanmartín Barros, "La cultura histórica sobre el 'año mil' en sus diferentes historiografías", Revista de História das Ideias, [vol.] 34 (2016): 87-111.

Álvaro Solano Fernández-Sordo, "Historia urbana en la Galicia medieval. Balance y perspectivas", Cuadernos de Estudios Gallegos, 123 (2010): 55-90. 


\section{Perfil}

Carmen Álvarez García es Máster en Métodos y Técnicas Avanzadas de Investigación Histórica por la Universidad Nacional de Educación a Distancia (UNED, España).

\section{Profile}

Carmen Álvarez García has a Master degree in Advanced Historical Research Methods and Techniques from the Universidad Nacional de Educación a Distancia (UNED, Spain).

Fecha de recepción: 25 de marzo de 2020

Fecha de aceptación: 18 de mayo de 2020

Publicación: 1 de julio de 2020

Para citar este artículo: Carmen Álvarez García, "Una aproximación a la historia medieval en Galicia entre los años 2007 y 2017", Historiografías, 19 (enero-junio, 2020), pp. 122-144. 